Sādhanā Vol. 39, Part 3, June 2014, pp. 699-711. (C) Indian Academy of Sciences

\title{
Applying the digital-image-correlation technique to measure the deformation of an old building's column retrofitted with steel plate in an in situ pushover test
}

\author{
SHIH-HENG TUNG ${ }^{1}$, MING-HSIANG SHIH $^{2, *}$ and \\ WEN-PEI SUNG ${ }^{3}$ \\ ${ }^{1}$ Department of Civil and Environmental Engineering, National University \\ of Kaohsiung, Kaohsiung 820, Taiwan \\ ${ }^{2}$ Department of Civil Engineering, National Chi Nan University, Nantou, Taiwan, \\ 1 University Road, Puli, Nantou 545, Taiwan \\ ${ }^{3}$ Department of Landscape Architecture, National Chin-Yi University of Technology, \\ Taichung 411, Taiwan \\ e-mail: iloveaachen@gmail.com
}

MS received 30 July 2013; revised 9 January 2014; accepted 17 January 2014

\begin{abstract}
An in situ pushover test is carried out on an old building of GuanMiao elementary school in south Taiwan. Columns of this building are seismically retrofitted with steel plate. The DIC (digital-image-correlation) technique is used to measure the deformation of the retrofitted column. The result shows that the DIC technique can be successfully applied to measure the relative displacement of the column. Additionally, this method leads to the measurement of relative displacements for many points on the column simultaneously. Hence, the column deformation curve, rotation and curvature can be determined using interpolation method. The resulting curvaturediagram reveals that the phenomenon of plastic hinge occurs at about $2 \%$ storey drift ratio, and that the DIC technique can be applied to measure column deformation in a full scale in situ test.
\end{abstract}

Keywords. Digital-image-correlation technique; full scale in situ test; push-over test; non-contact measurement technique.

\section{Introduction}

The Chi-Chi earthquake occurred on 21 September 1999 causing a great damage with many buildings destroyed or damaged. About $40 \%$ of the destroyed or damaged buildings are elementary or junior high school buildings. Because of safety concerns, several old but un-damaged

${ }^{*}$ For correspondence 
school buildings were scheduled to demolish; this provided a unique opportunity to carry out a series of in situ pushover tests on existing buildings for verifying the effectiveness of various retrofitting techniques. An in situ pushover test was organized on 26 July 2007 on a two storey old building of Guan-Miao elementary school built in 1950s in Tainan, Taiwan. Columns of this building were seismically retrofitted with steel plates because this building had been damaged by strong earthquake. If the traditional contact-type measurement techniques were used to measure the deformation of the building, the measurement instruments that were installed inside the building, must be removed at a certain degree of column deformation before the study was completed because of the safety reasons. Hence, a complete column deformation could not be measured using this traditional measurement technique.

The DIC technique was developed during the 1980s (Peters \& Ranson 1982; Chu et al 1985; Sutton et al 1991). It has been applied for analysing various structural problems. For example, French scholars Raffard et al (2001) applied DIC technique to measure the deformation of mortar for providing a further insight into mortar mechanics. Dost et al $(2003,1999)$ acquired nano-images using an atomic force microscope that assisted them in not only finding out the profiles of nano-materials but also analysing nano-displacement and nano-crack by integrating the DIC technique. Kuo et al (2003) and Zaefferer et al (2003) used the DIC technique to investigate the deformation of Aluminum Bicrystals. Shih et al (2008) applied the DIC technique to observe the crack development in masonry wall. One major advantage of DIC technique is its characteristic non-contact-type measurement so that the digital camera can be installed outside the building. Therefore, the characteristic of this developed DIC method can be applied to measure the full scale story drift of building under excitation of external force; this function cannot be provided by traditional measuring methods. In order to obtain a complete measurement of column deformation using a full scale in situ test in this study, this proposed DIC method is used to measure and analyse the mechanical phenomena of columns of this old building retrofitted with steel plates under excitation of large displacement.

\section{The DIC (Digital-Image-Correlation) method}

The principle of the DIC method lies in determining the local correlation of two sub-images to identify the mapping relationship between the selected sub-images before and after deformation based on the characteristic gray-scale distributions in the image of the structural speckle on the specimen surface. As shown in figure 1, the central point of sub-image $A$ prior to deformation is point $P$, and it moves to point $P^{*}$ after deformation while the corresponding sub-image is $B$. The correlation between the gray-scale pattern of sub-images $A$ and $B$ can be defined asthe COF (correlation coefficient) (Chu et al 1985):

$$
C O F=\frac{\Sigma g_{i j} \widetilde{g}_{\overline{i j}}}{\sqrt{\Sigma g_{i j}^{2} \cdot \Sigma \tilde{g}_{\overline{i j}}^{2}}},
$$

where: $g_{i j}$ and $\bar{g}_{i \bar{j}}$ is grayscale of sub-image $A$ on coordinate $(i, j)$ and sub-image $B$ on coordinate $(\bar{i}, \bar{j})$, respectively. In addition, coordinate $(\bar{i}, \bar{j})$ of sub-image $B$ corresponds to coordinate $(i, j)$ of sub-image $A$. The maximum $\mathrm{COF}$ is equal to 1 when the sub-image $B$ coincides with the image of sub-image $A$ after deformation, and $P^{*}$ is the position of $P$ after deformation. 


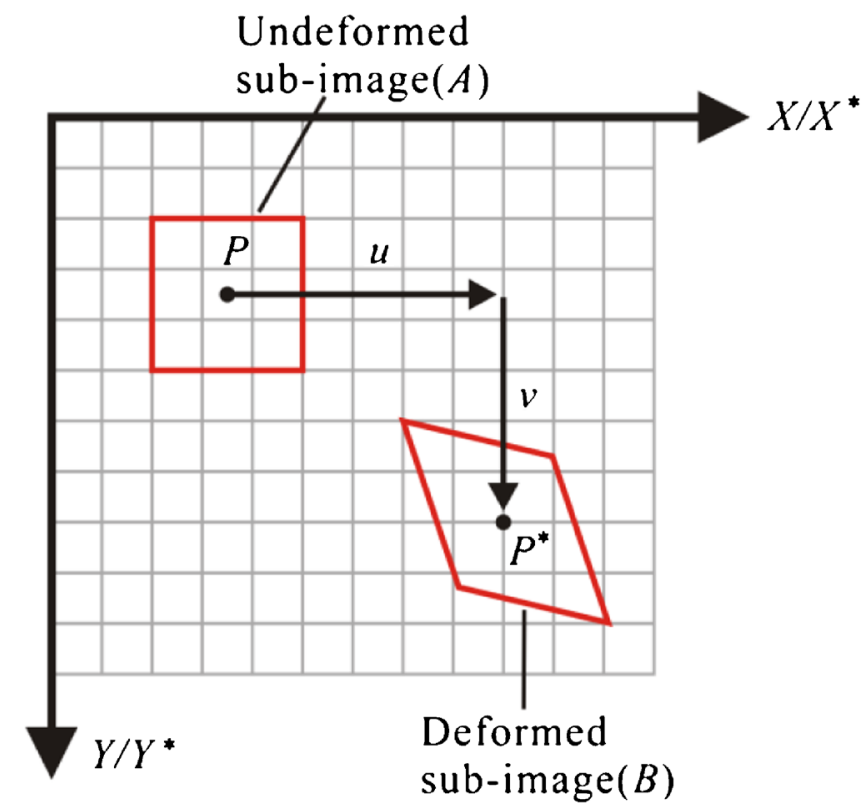

Figure 1. Schematic drawing of relative location of sub-images of deformed and un-deformed images.

\section{The full scale pushover test}

The specimen of this test was an old two-storey reinforced concrete building of Guan-Miao elementary school in Tainan, Taiwan. Four test specimens are planned, and this research focuses on specimen no. 1, which had been retrofitted with steel plate.

Schematic diagram of the test arrangement is shown in figure 2. If the building is viewed from the front side, specimen no. 1 is seen to compose of the four two-storey classrooms at the left end of the building. The specimen was separated from the rest of the building by cutting the connecting floor, roof and walls. It was pushed at the position of the beams from the right side of the specimen with four actuators installed on the beams of the right building. Therefore, the necessary reaction force was provided by the right section of the building that has been reinforced with six steel braces to avoid the occurrence of unnecessary large-scale deformation.

The elevation and plane of the specimen are shown in figure 3 . The beams and only columns A2, A4 and C2, C4 were retrofitted with steel plates; the other columns are unchanged. As shown in figure 4 , all of these four columns have identical cross. The retrofit of columns A2 and

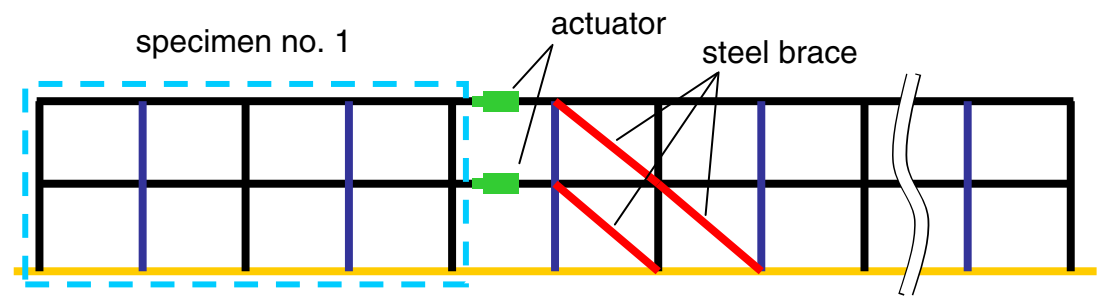

Figure 2. Schematic drawing of the test arrangement for the two-storey building as seen from the front. 


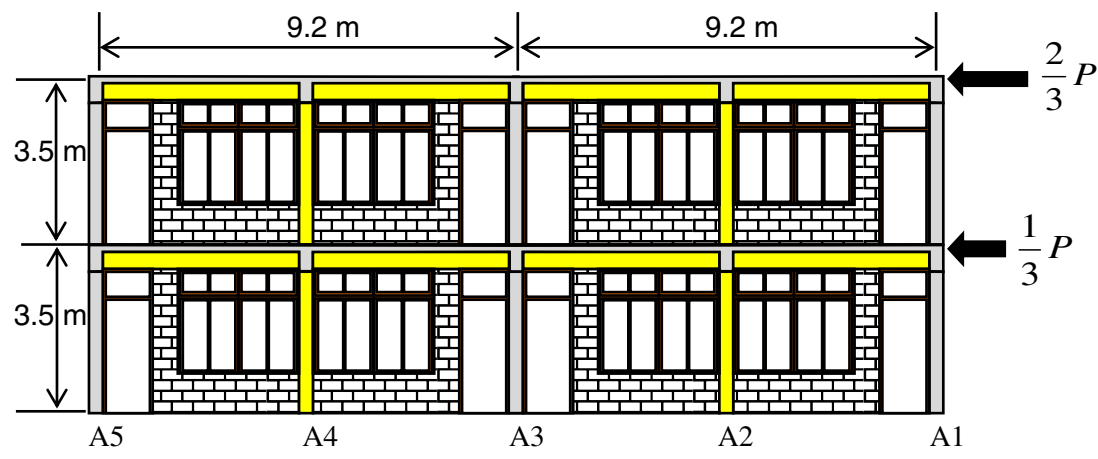

(a)

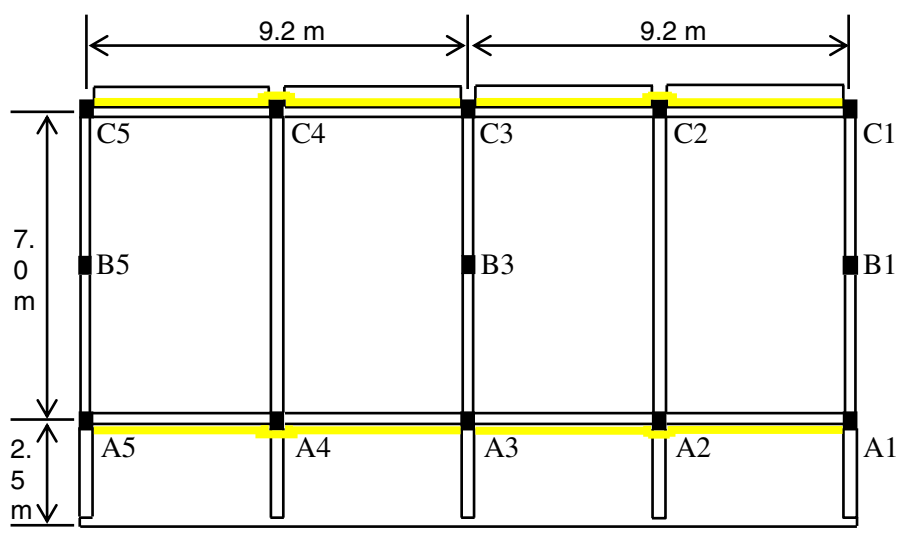

(b)

Figure 3. Schematic drawing of (a) elevation and (b) plane of specimen no. 1.

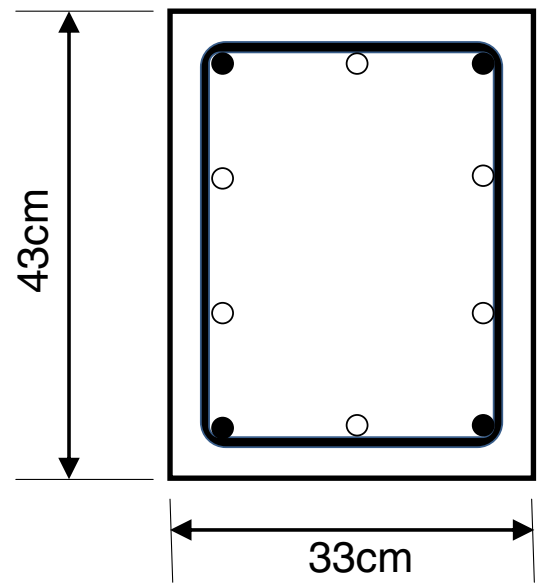

$f c^{\prime}=20.2 \mathrm{MPa}$

$f y=312 \mathrm{MPa}$

4-D22

6-D19

D10@20 cm

Figure 4. Cross section of column A2 and A4. 
A4 are shown in figure 5. The specimen was pushed from the right side with the ratio of the force applied at the beam of the first floor to the force applied at the beam of the ground floor maintained at 2 during the test.

During the test, the pushing was paused at the storey drift ratio of $0.25,0.5,0.75,1.0,1.25$, $1.5,1.75,2.0,2.5$ and $3.0 \%$ that is defined as the ratio of lateral displacement of roof to the height of the roof. The observed cracks are marked during the pause. At the $2.5 \%$ storey drift ratio, the traditional measurement instruments, if used, need to be removed from the specimen for safety concerns as mentioned earlier. Therefore, the complete deformation history at large deformation can no longer be obtained. However, the measurement based on the DIC technique can be continued beyond the $2.5 \%$ storey drift ratio. After $3 \%$ storey drift ratio, the test was paused at 3.5, 4, 5 and $6 \%$ storey drift ratio for only a short time. Afterward, the specimen was pushed over completely.

According to Chiu's research (Chiu 2008), there are significant differences between the seismic performance of the original and the retrofitted building in this pushover test. Compared

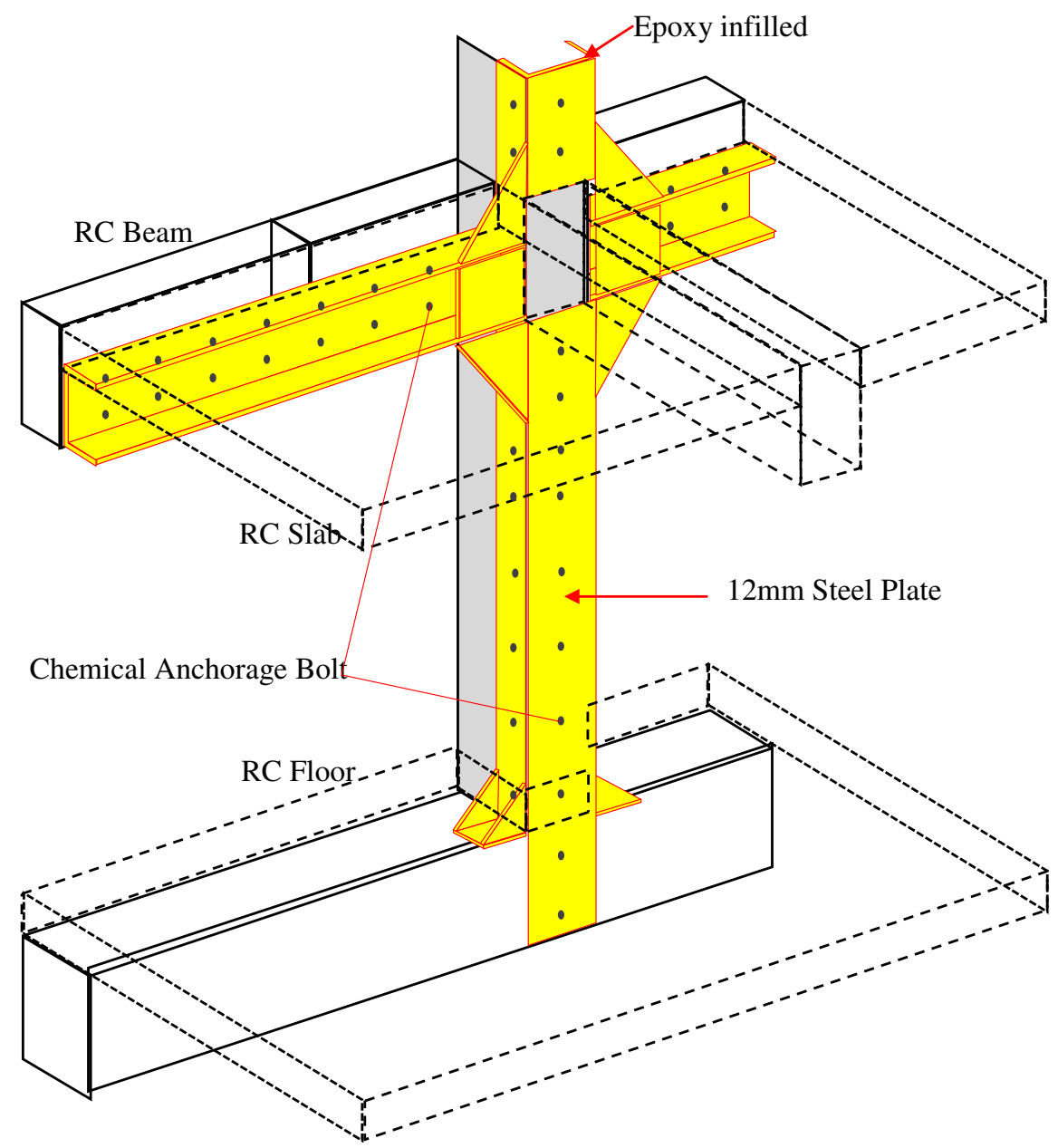

Figure 5. Retrofit of column A2 and A4 with $12 \mathrm{~mm}$ steel plate. 
with the original building, the base-shear capacity of the retrofitted building has increased nearly $110 \%$, and the energy-dissipation has also increased $120 \%$ due to its better ductility.

\section{Method of image acquisition and analysis}

\subsection{Image acquisition method}

Figure 6a shows the image of column A4 marked with both the regular signs (as shown in figure $6 \mathrm{~b}$ ) and painted irregular signs (figure 6c). To avoid disturbing the observation of other research teams, the distribution of marks on the surface of column A4 is not very dense.

Canon EOS 300D DSLR camera equipped with SIGMA 18-200mm F3.5-6.3 DC lens was used to capture the digital images of column A4. The camera was fixed before the column A4 at a distance about $10 \mathrm{~m}$ from the column. Figure 7 shows the images of column A4 at the storey drift ratio of $0,1,2$ and $3 \%$.

\subsection{Image analysis}

The DIC technique is used to analyse the column deformation. After the position of every mark is traced, two parallel observation lines on the surface of column (as shown in figure 8) are chosen. There are 181 equal spaced points on each line. The positions of these points are calculated using B-Spline interpolation function based on the positions of the traced points. The results are

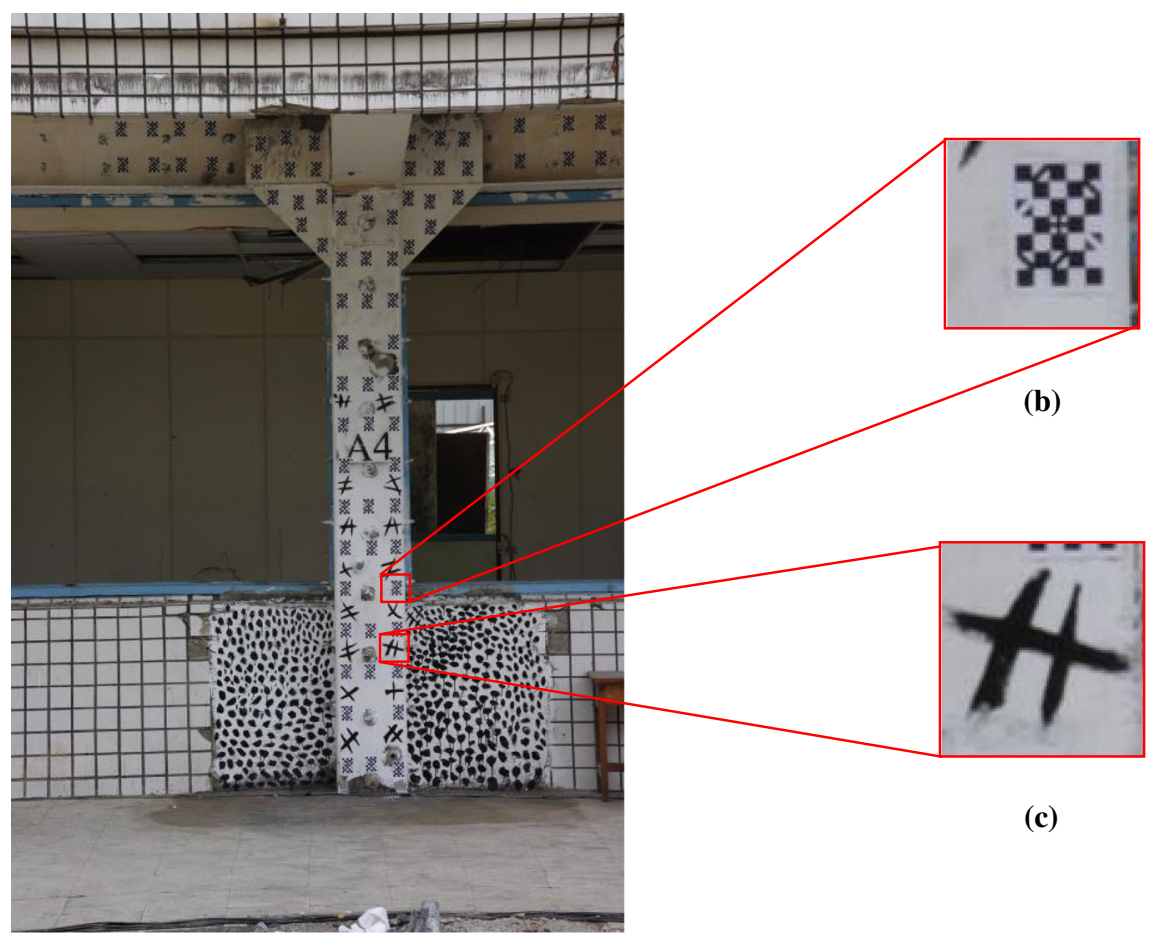

(a)

Figure 6. (a) Image of marked column A4, (b) regular signs, and (c) irregular signs. 


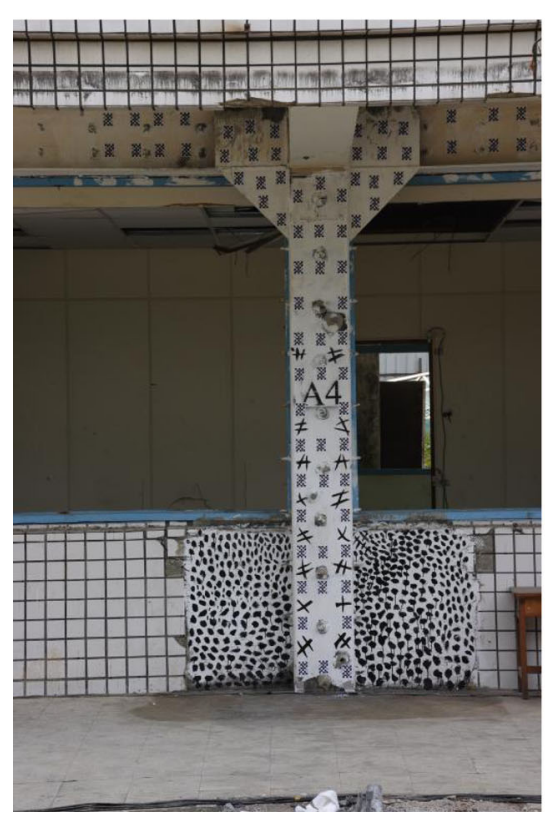

(a) $0 \%$

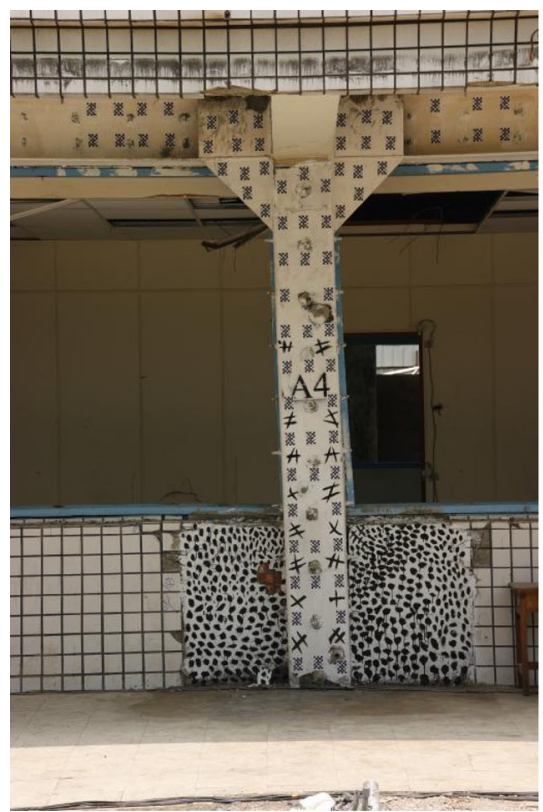

(c) $2.0 \%$

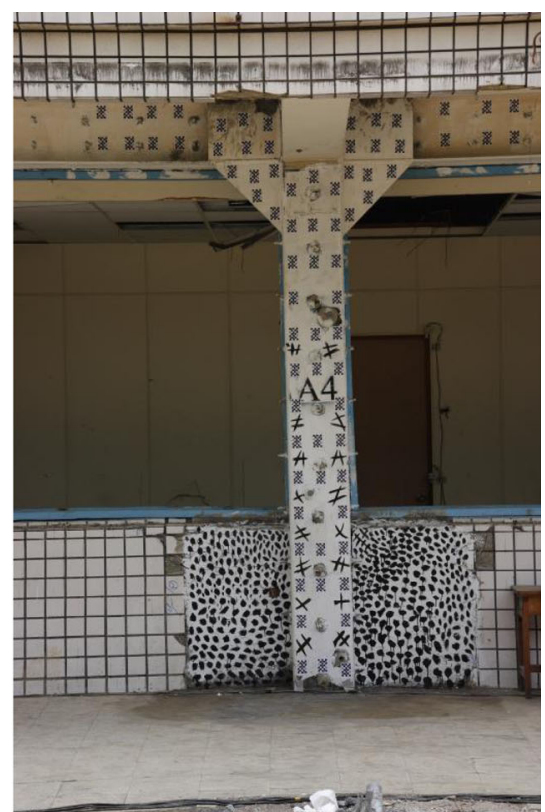

(b) $1.0 \%$

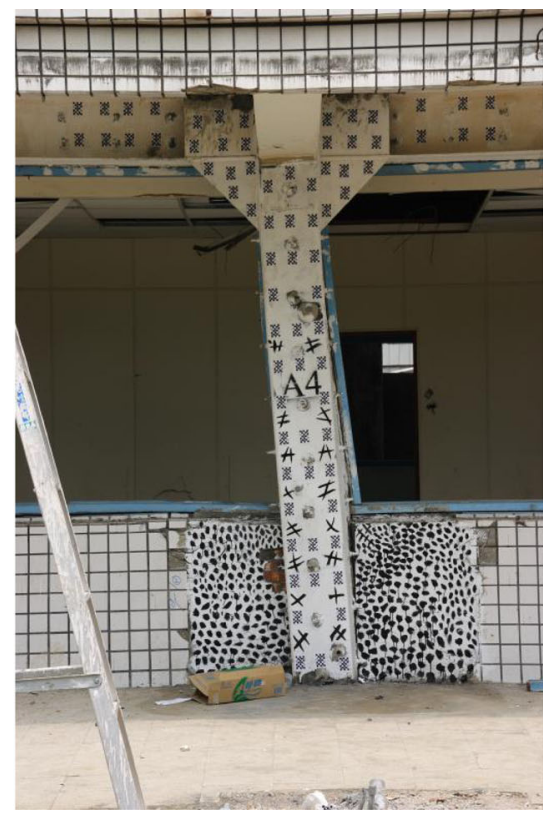

(d) $3.0 \%$

Figure 7. Images of the column A4 at different storey drift ratio. 


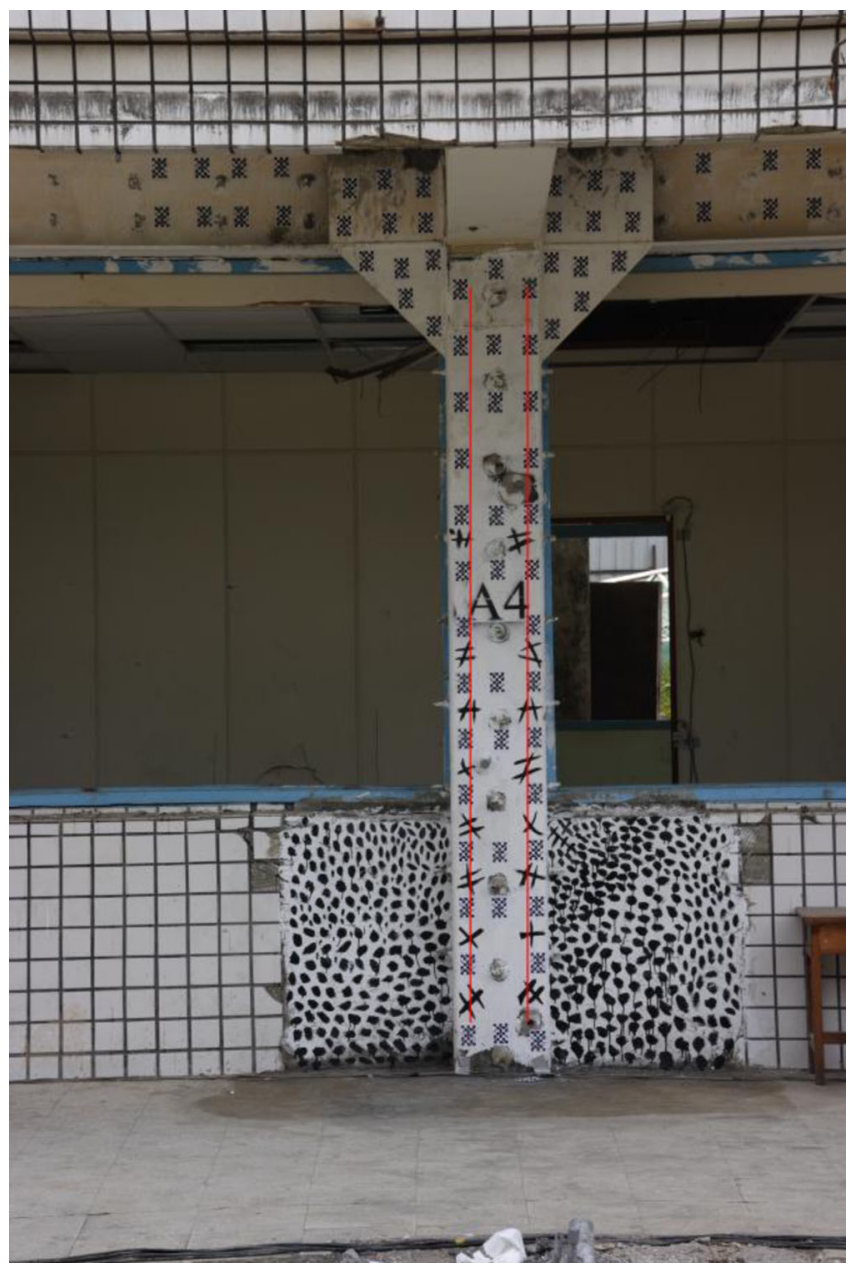

Figure 8. The locations of two observation lines.

then used to evaluate the lateral displacement, storey drift ratio, and rotation and curvature of column A4.

\section{Analytical results of digital images}

Figure 9 shows the relative lateral displacement, which is the average displacement of both observation lines, of column A4 at different heights. The lower end point of the left observation line is used as the reference point for all lateral displacement. The difference of theoretical storey drift ratio between two adjacent curves is $0.5 \%$. Figure 9 reveals that all lateral displacement differences between every two adjacent curves at the same height remain unchanged before $2 \%$ storey drift ratio is reached. The increment of lateral displacement is obviously greater after the storey drift ratio reaches $2 \%$, and the plastic hinge seems to be formed in column A4 at about $2 \%$ storey drift ratio. The results for the drift ratios larger than $3 \%$ are not displayed because the steel plate began to separate from the column, and obvious out-of-plane movement occurred. 


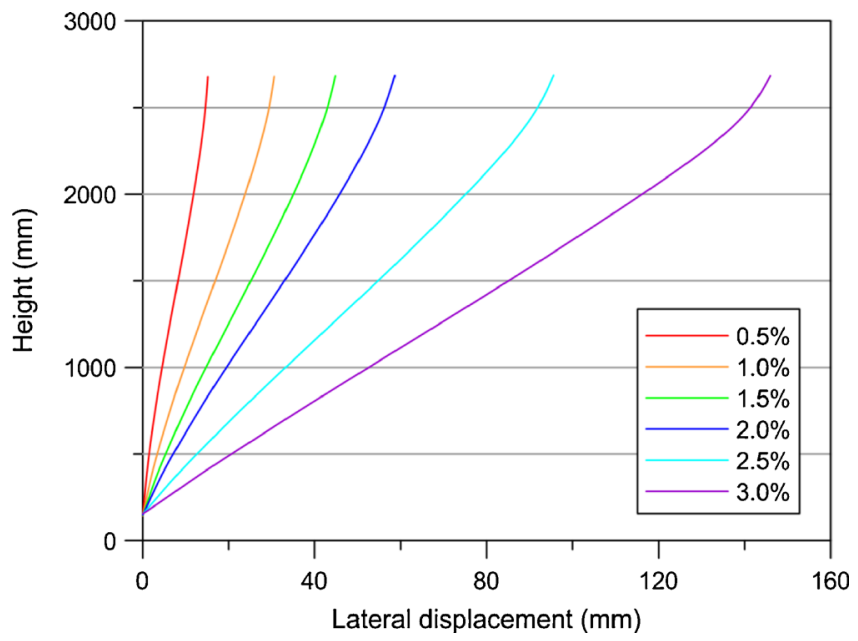

Figure 9. The lateral displacement of column A4 at different storey drift ratio.

If the lateral displacement difference of the two end points of the observation line is divided by the vertical distance between these two points, the measured storey drift ratio of ground floor can be obtained. The relationship between measured and scheduled storey drift ratio is shown in figure 10 (the blue line); it diverges from 1 because the length of the observation line is not equal to the height of the ground floor.

The rotational angles at different heights of various storey drift ratios are shown in figure 11 . Because of the constraints of beam and foundation beam, the top and bottom of column A4

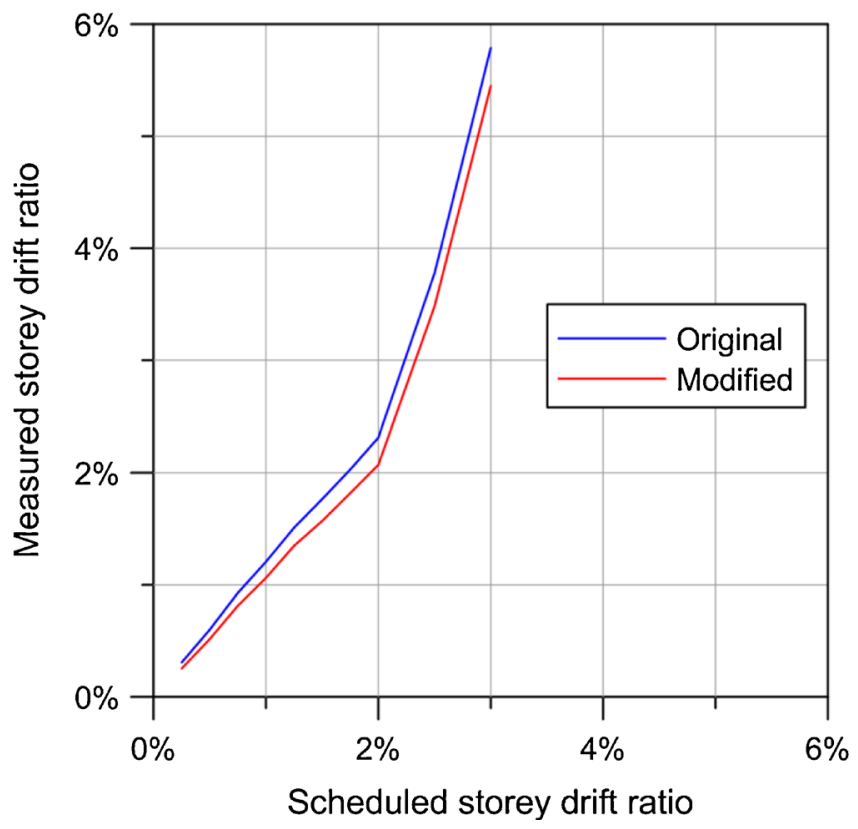

Figure 10. The relationship between the measured and scheduled storey drift ratio. 


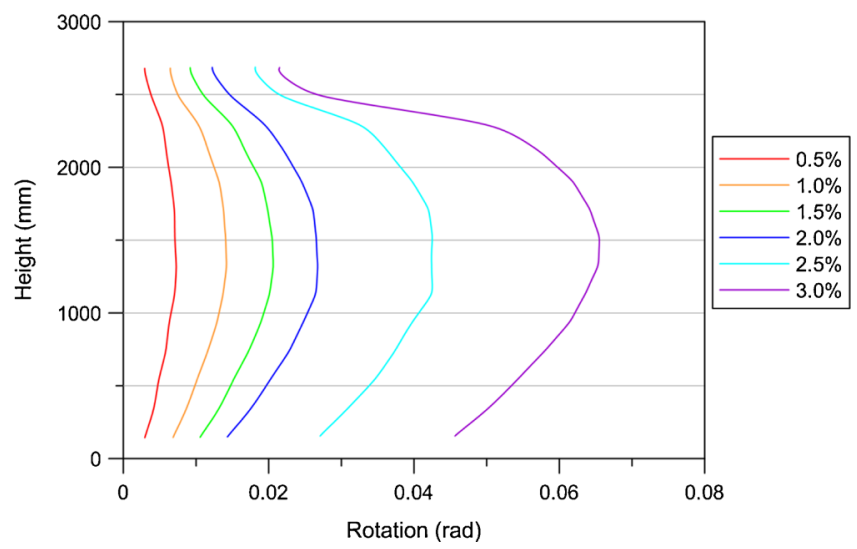

Figure 11. The rotation angle of column A4 at different storey drift ratio.

have smaller rotational angles than the middle part of the column. Before $2 \%$ storey drift ratio is reached, rotational angles of the observation line are almost the same for both ends of the column. After the storey drift ratio exceeds $2 \%$, the column bottom obviously has greater rotation angle than the column top. The photograph reveals that the ground near column bottom heaves indicate damages to the foundation beam-column joint. This situation is more serious for $3 \%$ storey drift ratio.

The difference method is used to calculate the curvatures of every interpolation points for both observation lines. The results shown in figure 12 indicate that the noise is not small. But all the curves between the column height 50 and $200 \mathrm{~cm}$ are almost linear. Near the heights of 30 and $250 \mathrm{~cm}$, the variations of curvature are quite large. This means that plastic hinge occurs at these two positions.

The column section discussed in this paper is a composite section of concrete, steel and retrofitted steel plate. The retrofit method is shown in figure 5. Because the retrofitted steel plate is combined with the original reinforced concrete section by chemical anchors and epoxy, the stress distribution cannot be correctly defined. Therefore, the curvature of plastic hinge of this section can only be estimated approximately. The column observed in this research is the central column, so its axial force can be assumed to be constant. The total weight of the structure is $2.822 \mathrm{MN}$, and this load is equally supported by 10 columns, so each column subjected to an axial force of $282.2 \mathrm{kN}$.

If we estimate the curvature of plastic hinge by only considering the original reinforced concrete section, the following assumptions should be met:

(i) Reinforcements on the tension side yield.

(ii) Concrete on the compression side reaches the strain of 0.003 .

Assuming the reinforcements on the tension side yield, the total tension force of these four lateral reinforcements $(\mathrm{D} 22 \times 2$ and D19 $\times 2$ ) is $414.1 \mathrm{kN}$. Therefore, the neutral axis is $11.1 \mathrm{~cm}$ from the outer edge on the compression side. If the concrete strain on the compression side reaches 0.003 , the corresponding curvature can then be calculated by dividing the strain $(0.003)$ with the depth of neutral axis $(11.1 \mathrm{~cm})$ and this yields a curvature of plastic hinge $0.0270(1 / \mathrm{m})$. 

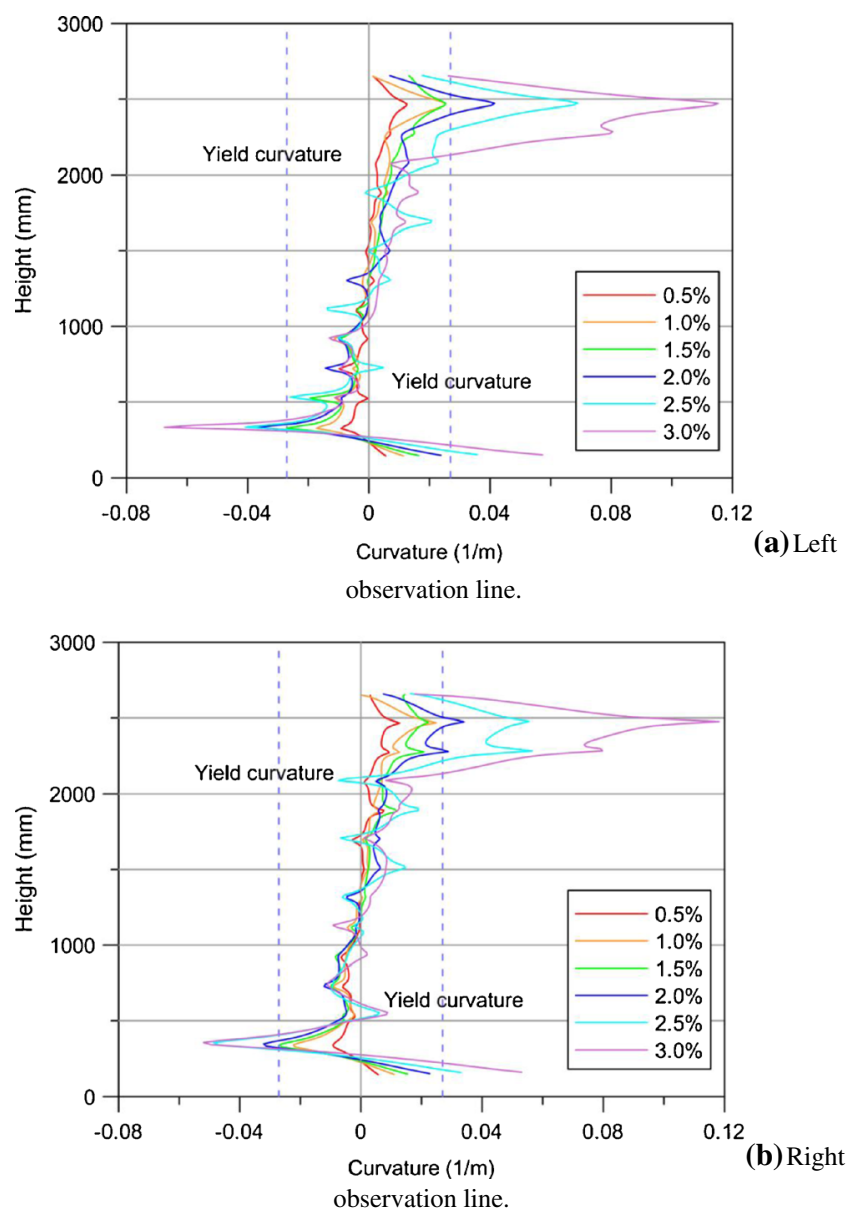

Figure 12. The curvature at different height of column A4.

When the stress of retrofitted steel plate is considered, the depth of neutral axis will be greater than $11.1 \mathrm{~cm}$, and the corresponding curvature will be less than $0.0270(1 / \mathrm{m})$. Therefore, classifying a section with a curvature greater than $0.0270(1 / \mathrm{m})$ as a plastic section is relatively conservative. Therefore, $0.0270(1 / \mathrm{m})$ is defined as the plastic hinge curvature in this paper.

This plastic hinge curvature is displayed by light blue straight lines in figure 12. Therefore, the range of plastic hinge, which is found to begin at about $2 \%$ storey drift ratio, spreads as the storey drift ratio increases from 2 to $3 \%$. The length of the plastic hinge grows from about 20 to $50 \mathrm{~cm}$, and it is smaller near the column bottom than that near the column top.

The results of figures 11 and 12 can be used to explain why the slope of the blue line in figure 10 diverges from 1 , and why the slope increases rapidly after $2 \%$ storey drift ratio. The length of the observation line is $253.5 \mathrm{~cm}$ and the height of this storey is $350 \mathrm{~cm}$. Therefore, the difference between the observation line length and the storey height is about $1 \mathrm{~m}$. There is still small rotation at both ends of the observation line, and the rotational angle at lower end of the 
observation line is greater than that at upper end of the observation line, and the lower end of the observation line is not far from the bottom of the column. If the difference of the rotational angle between the both ends of the observation line is ignored, the product of (1) the rotation angle at upper end of the observation line, and (2) the difference between the storey height and the length of the observation line can be used to modify the horizontal displacement of the ceiling relative to the ground. The modified storey drift ratio can be calculated by dividing the modified horizontal displacement by the storey height $(350 \mathrm{~cm})$. The relationship between the modified and the scheduled storey drift ratio is shown in figure 10 as the red line whose slope is equal to about 1 before the storey drift ratio reaches $2 \%$.

Figure 12 shows that the plastic hinge really occurs. The resistance of the ground floor is reduced after the occurrence of plastic hinge causing the deformation of the first floor to recover. Therefore, almost all of the deformation will occur on the ground floor; this results in a dramatic increment of the lateral displacement of ground floor. The slope of the lines, shown in figure 10, increases obviously when the storey drift ratio is greater than $2 \%$. However, the slope of the lines in figure 10 should not be greater than 2 even when all deformations occur on the ground floor. This situation can be explained with the following two reasons. First, as mentioned above, the deformation recovery of the first floor leads to an obvious increment of the lateral displacement of the ground floor. Second, the rotational angle at the upper end of the observation line is used to modify the horizontal displacement. However, after the occurrence of the plastic hinge, the rotational angle in the region higher than the upper end of the observation line varies continuously. The photo reveals that the rotational angle near the beam is already very small. Therefore, the modified horizontal displacement of the ground floor is overestimated. The combination of these two explanations accounts for the slope of the modified line in figure being greater than 2 .

\section{Conclusions}

The DIC technique is applied to measuring column deformation in a full scale in situ pushover test. The following conclusions can be drawn according to the analysis results.

(i) The modified storey drift ratio based on field data is almost the same as the scheduled storey drift ratio before $2 \%$ storey drift ratio is reached. This confirms that the accuracy of the DIC technique is excellent, and the DIC technique can be successfully applied to measuring column deformation in a full scale test.

(ii) The occurrence of the plastic hinge with its position and length can be determined by this proposed method.

(iii) Both the regular and irregular signs can be used to mark the specimen for detecting the deformation of columns by using this DIC method.

(iv) Because the column surface is not fully marked, only the position of the marked points can be traced. Consequently, the coordinates of the points in the observation line must be calculated by using interpolating method. If the column surface can be fully paved with the speckles, then the point position can be directly determined to increase the accuracy so that the noise shown in figure 12 will be greatly reduced.

All the experimental and analysis results demonstrate that this DIC method is useful for measuring the full-scale displacement of building. Therefore, this DIC method can be applied to detect the small, medium and large deformation of building subjected to external force. 


\section{Acknowledgements}

This work has been supported by the National Science Council of Taiwan, ROC through grant no. NSC 100-2625-M-260-001. This support is gratefully acknowledged.

\section{References}

Chiu Y C 2008 Field test and analysis for school building retrofitted by steel-framing system, Master's thesis, National Cheng Kung University.

Chu T C, Ranson W F, Sutton M A and Peters W H 1985 Application of digital-image-correlation techniques to experimental mechanics. Experimental Mech. 25(3): 232-244

Dost M, Rümmler N, Kieselstein E, Erb R, Hillmann V and Großer V 1999 Correlation analysis at grey scale patterns in an in-situ measuring module for microsystem technology. Mater. Mech. Fracture Mech. - Micromech. Winkler T and Schubert A (eds.) pp. 259-266, Berlin/ Chemnitz

Dost M, Vogel D, Winkler T, Vogel J, Erb R and Kieselstein E 2003 How to detect Edgar Allan Poe's 'purloined letter' - or: Cross correlation algorithms in digitised video images for object identification, movement evaluation and deformation analysis. Nondestructive Detection and Measurement for Homeland Security, Proceedings of SPIE Vol. 5048

Kuo J C, Zaefferer S, Zhao Z, Winning M and Raabe D 2003 Deformation behavior of aluminum bicrystals. Advanced Eng. Mater. 5: 563-566

Peters W H and Ranson W F 1982 Digital imaging techniques in experimental stress analysis. Optical Eng. 21(3): 427-432

Raffard D, Ienny P and Henry J-P 2001 Displacement and strain fields at a stone/mortar interface by digital image processing. J. Testing and Evaluation 29(2): 115-122

Shih M H, Tung S H and Sung W P 2008 Development of digital image correlation method to analyze crack variations of masonry wall. Sadhana Academy Proc. Eng. Sci. 33(6): 767-779

Sutton M A, Turner J L, Bruck H A and Chae T A 1991 Full-field representation of discretely sampled surface deformation for displacement and strain analysis. Experimental Mech. 31: 168-177

Zaefferer S, Kuo J C, Zhao Z, Winning M and Raabe D 2003 On the influence of the grain boundary misorientation on the plastic deformation of aluminum bicrystals. Acta Materialia 51: 4719-4735 